\title{
Artigo
}

\section{Aspectos cognitivos e noções de justiça social da política externa brasileira: eixos conceituais}

Cognitive aspects and notions of social justice of Brazilian foreign policy:

conceptual axes

DOI: $10.5752 /$ P.1809-6182.2017v14.n1.p4

Luiz Henrique Dias da Silva ${ }^{1}$

Recebido em: 17 de outubro de 2015

Aprovado em: 25 de maio de 2016

\section{RESUMO}

O Brasil é um pais de tradição pacifista cujo discurso apela ao Direito Internacional, à solução pacífica de controvérsias e ao multilateralismo. Assim, torna-se pertinente analisar os eixos conceituais de sua diplomacia e politica externa comparados à realidade sistêmica. Palavras-chave: Politica Externa. Justiça Social. Multilateralismo.

\section{ABSTRACT}

Brazil is a country of pacifist tradition whose discourse appeals to international law, the peaceful settlement of disputes and multilateralism. Thus, it is relevant to examine the conceptual axes of its diplomacy and foreign policy compared to systemic reality.

Keywords: Foreign Policy. Social Justice. Multilateralism.

1. Doutorando em Relaçôes Internacionais pela Pontifícia Universidade Católica de Minas Gerais. Mestre em Relaçôes Internacionais pela Pontifícia Universidade Católica de Minas Gerais (1/2017). Bacharel em Relaçóes Internacionais pelo Centro Universitário de Belo Horizonte. Estagiário em docência PPGRI PUC Minas. ORCID: 0000-0001-8749-0871 


\section{Eixos conceitucis da política externa brasileira}

Os eixos conceituais da diplomacia brasileira que permitem evocar a tradiçáo pacífica, conciliadora, de respeito à soberania, à autodeterminação dos povos e à soluçóes multilaterais ancoradas em mecanismos pacíficos de solução de controvérsias encontram-se na formulação da Política Externa Independente (PEI) ${ }^{2}$. Praticada entre 1961 e 1964 pelos governos Jânio Quadros e João Goulart, respectivamente, a PEI começou a ganhar contornos efetivos no ano de 1958 a partir da síntese do pensamento de Gonzalo J. Fácio, Oswaldo Aranha e José Garrido Torres (CERVO, 1998). Filiados à Revista Brasileira de Relaçóes Internacionais (RBPI), estes autores elaboraram um discurso pacifista especialmente voltado ao desarmamento da América Latina (AL), visando à inversão de recursos militares ao desenvolvimento regional.

Some-se a isso, a integração econômica para a América Latina proposta pela Operação Pan Americana (OPA), de Juscelino Kubitschek (JK). O Brasil deveria livrar-se da subserviência aos Estados Unidos da América (EUA) em ação concertada com as naçóes subdesenvolvidas do continente, ideia essa adotada por Jânio Quadros, que a estendeu para uma parceria com países africanos. Não por acaso, esta é uma referência constante nos discursos brasileiros na Organizaçấo das Naçôes Unidas (ONU) no período de descolonização da África. Também importante nesse alicerce conceitual da política externa brasileira é o papel da elite intelectual marxista, de filiação gramsciana, na persecução de um projeto desenvolvimentista industrial e de integração regional voltado ao não confrontacionismo (GARROT, 1998).

2. Embora o multilateralismo ainda não constasse do discurso, Cervo e Bueno (2002) apontam 1844, ano de rompimento dos Acordos Desiguais com a Inglaterra, como antecedente mais remoto dos eixos conceituais da PEI.
A elite marxista incorpora, além da Teoria do Poder, de Antônio Gramsci, conceitos de centro-periferia enunciados por Fernand Braudel em apêndice à Teoria da Dependência. Pensadores estruturalistas da Comissão Econômica para a América Latina (CEPAL), como Raúl Prebish e Celso Furtado, têm o coro engrossado pelas vozes marxistas de Caio Prado Jr. e Edgard Carone, além de Gerson Moura, estudioso de assuntos europeus. Há nestes autores a recusa a recursos militares, a busca por soluções pacíficas e o respeito aos tratados em funçáo do desenvolvimento e da modernização. Este preponderante pensamento marxista dá forma ao antiamericanismo dos anos 1960, à busca por um mercado comum do Sul e ao caráter antibelicista da política externa brasileira. Favorecia-se o pacifismo porque ambientes de integração não se desenvolvem em meio a guerras (GARROT, 1998).

\section{A PEB dos militores e a transição democrática}

Não se pode considerar o golpe militar de 1964 uma ruptura definitiva com os eixos conceituais da política externa independente, uma vez que, durante os 21 anos de governos militares, apenas Castelo Branco (1964 - 1966) e Ernesto Geisel (1974 -1979) alinharam-se automaticamente à política externa estadunidense. O primeiro praticou o 'passo fora da cadência', uma política de (inter) dependência atrelada a um modelo de desenvolvimento nacional associado ao capital internacional em favor da burguesia brasileira (CERVO; BUENO, 2002). Porém, seu sucessor, Costa e Silva (1967 - 1969) retoma a busca por desenvolvimento como objetivo de política externa. Nesse sentido, há denúncias de injustiças do sistema internacional, diz-se não ao Tratado de Não-Proliferação Nuclear (TNP) e renovam-se conflitos ideológicos com os EUA, em nome do reajuste do interesse nacional. 
Com o recrudescimento da Guerra Fria e o momento interno brasileiro de agitação social, estabelece-se no governo seguinte, Médici, (1969 - 1974) uma junta militar cuja diplomacia visa aumentar a autonomia do interesse nacional. Durante o 'Milagre Econômico', um nacionalismo autoritário busca novos mercados e capital privado. Geisel, por sua vez, praticou o pragmatismo responsável, uma política externa desideologizada, muito em funçâo das crises do petróleo, de atritos com os EUA nas áreas nuclear/militar, bem como acirramento da crise do modelo desenvolvimentista, obrigando a uma maior abertura política. Após essa nova ruptura, o Brasil pratica uma política externa dita universalista sob o general João Batista Figueiredo (1979-1985). O país busca divisas para fugir de múltiplas crises, abrindo-se ao impulso liberal do sistema. Este é o período em que o modelo nacional desenvolvimentista arrefece em meio à transição democrática (CERVO; BUENO, 2002).

Já em meados dos anos 1980, vivia-se internamente o período de distensão democrática, com o primeiro presidente civil, José Sarney, após 21 anos de ditadura militar. No plano internacional, Mikhail Gorbatchev ascendia ao poder na Uniāo das Repúblicas Socialistas Soviéticas (URSS). Gorbatchev conduziu a glasnost - abertura ou transparência política, que, aliada à perestroika - reestruturação econômica, reaproximou a URSS dos EUA (SEIXAS CORRÊA, 2007). Tal acontece em um momento em que o modelo de economia planificada dava mostras de desgaste. A queda da URSS e sua dissolução em 15 Estados independentes marcam o fim da Guerra Fria e da bipolaridade, dando início a novas interações no ambiente internacional.

Nesse contexto, o discurso brasileiro critica a imposição unilateral dos EUA. Em contraposição, o presidente Sarney (2007, pp. 445 - 459), na abertura da XL Sessão Ordinária da Assembleia Geral da Organização das Naçôes Unidas, no ano de 1985, apresenta o Brasil como modelo de resolução pacífica de controvérsias e fomento à integração regional. Apresentam-se exemplos como o fim da ditadura e entrada na senda democrática por parte dos países da América Latina, o restabelecimento de relaçôes diplomáticas com Cuba, o Mercado Comum das Américas (MERCOSUL), a formação da Agência Brasileiro-Argentina de Controle de Materiais $\mathrm{Nu}$ cleares (ABACC) e a assinatura do Tratado de Tlatelolco (1967), que tornou a América Latina a primeira regiáo habitada pelo homem totalmente desarmada nuclearmente. O discurso de Sarney reitera o fato de a América Latina ter um reduzido orçamento militar, em crítica ao militarismo estadunidense.

\section{Segurança em tempos de paz}

Quando apela à ONU como representante do multilateralismo e da resolução pacífica de controvérsias, o discurso brasileiro remete ao conceito de poder causal (KOLODZIEJ, 2005). Por este viés, a estrutura de poder que os Estados criam através de suas interações reflete sua disposição para o uso ou não da força. Também neste sentido, a ONU apresenta-se como um minissistema causal onde o Brasil, por meio da renitente reiteração de sua tradição pacífica busca auferir ganhos relativos no sistema internacional. Raras são as ocasiōes em que o representante brasileiro não se aproveita de períodos de transformação estrutural para reivindicar assento permanente no Conselho de Segurança da ONU ou, em última instância, reforma no órgão para melhor refletir a ordem multilateral.

Atento à segurança em tempos de paz, o Brasil faz referência ao Direito Internacional, respeito à igualdade jurídica entre Estados, e à segurança dada pelo respeito aos tratados, aos regimes e instituiçóes da ordem democrática (KOLODZIEJ, 2005). Assuntos como economia, cooperação e proteção ambiental fogem da lógica de segurança, entrando 
no escopo mais amplo das relaçóes internacionais. Assim, o Brasil não é contrário a embargos, salvaguardas ou tarifaçóes especiais, desde que de acordo com o Direito Internacional e que não se recorra ao uso da força no sentido de violência como forma de alterar o estado das coisas.

\section{A ordem democrática global}

O nível sistêmico reflete a disposição dos Estados em usar ou não a força, assim como as pressôes a que cada ator está submetido. Além disso, nesse nível há que sopesar entre ganhos relativos (poder) ou absolutos (comércio e investimento) a posição que o Estado pode ocupar conforme suas decisóes. Isso em nada difere dos cálculos brasileiros e do uso do estoque diplomático tradicionalmente pacifista e ordeiro. Pregar a favor do multilateralismo em momentos em que o liberalismo à moda norte-americana parece capitular é parte do discurso desde que o Brasil se percebeu preterido na ordem internacional em favor da reconstrução da Europa e ex-colônias europeias na África e na Ásia no pós-Segunda Grande Guerra (CERVO; BUENO, 2002).

No nível Estado-sociedade civil, opta-se por restringir o poder do uso da violência por parte do Estado em prol do bem-estar social e acesso à tecnologia. Tal acontece com o empoderamento de atores transnacionais. Os atores-chave por trás desse aparente limite do histórico poder coercitivo do Estado são as instituições ligadas aos mercados globais, os bancos do Sistema Breton Woods e organizaçōes da família onusiana, como a Organização Mundial do Comércio (OMC) (KOLODZIEJ, 2005).

Essas instituições, empresas e organizações fazem parte das conquistas de liberdade de ação da sociedade civil e embora estejam associadas à exploraçấo de Estados menos favorecidos, também integram o discurso brasileiro no sentido de que são instituições cuja operação inclui trocas sociais.
Já no nível Estado-ordem doméstica, figuram os regimes democráticos como os mais favoráveis à limitação da violência estatal. Assim, liberdades civis e defesa dos direitos humanos fazem parte do discurso brasileiro na ONU especialmente a partir de 1985, quando o Brasil sai de um período de 21 anos de ditadura militar e volta a ter um governo civil (SEIXAS CORRÊA, 2007).

\section{A via pacífica nem sempre funciona}

É interessante notar, no entanto, que a solução pacífica de controvérsias nem sempre funcionou. Após o fim da Guerra Fria iniciou-se um período de maior cooperação entre as potências, tendo as guerras sido transferidas para regióes periféricas, ficando estas restritas muitas vezes a conflitos domésticos pós-descolonização. Os anos 1990 também forneceram vários laboratórios para testar os mecanismos de soluçáo pacífica de controvérsia, além da diplomacia de segunda via, de figuras proeminentes da política internacional como o ex-presidente dos EUA, Jimmy Carter. Porém, vários foram os fracassos, desde as negociaçóes secretas de Carter com a Coreia do Norte para que parasse com seu programa nuclear, até os fiascos das intervençóes humanitárias na Bósnia (1992 - 95), Somália (1992 - 93) e o colapso do processo de paz entre Israel e Palestina (2000) (MIALL; RAMSBOTHAM; WOODHOUSE, 2005, p. 5).

Naquele período, a ONU declarou a prevenção de conflitos como Meta do Milênio, mas a iniciativa esbarrou em uma multiplicidade de interpretaçóes e dificuldades domésticas diversas, além do crescente tráfico de armas dentro da lucrativa indústria da guerra. Além disso, não se contava com o uso de armamento barato e adequado às guerras assimétricas que eram travadas, além de uma espiral de conflitos gerada pela falta de perspectiva de melhoria econô- 
mica para os povos em guerra (MIALL et al., 2005). Ao Brasil, esses fracassos da ONU, dos EUA e de parceiros como a Organização do Tratado do Atlântico Norte (OTAN) náo passaram despercebidos.

Em discurso no ano de 1994, o ministro Celso Amorim ressaltou que o mundo estava distante da paz universal, referindo-se especificamente à Ruanda, Bósnia-Herzegovina e Angola. Questionava-se a globalização e o livre comércio em sua capacidade de prover o bem estar a nível global, no sentido de que a globalização mais acirra do que diminui as diferenças culturais (KOLODZIEJ, 2005). Criticava-se ainda a polarização entre as Naçóes Unidas de um lado e o Sistema Breton Woods do outro. Dizia o ministro: "há que se repensar em profundidade a atuação das Naçôes Unidas na promoção do desenvolvimento" (AMORIM, 2007, p. 586).

No ano seguinte, Felipe Lampreia (governo FHC), discursou sobre os impactos da desastrosa campanha da ONU na Iugoslávia e o desfecho sangrento protagonizado pela OTAN. O ministro afirmou que o conflito ficaria como "exemplo vivo dos fracassos do passado e dos desafios e percepçóes equivocadas do presente" (LAMPREIA, 2007, p. 592). Aproveitou ainda para pregar a reforma do Conselho de Segurança, condenar os testes nucleares franceses e solicitar que a ONU fosse instrumentalizada para enfrentar os desafios de seu tempo, não sem evocar a adequação das mais tradicionais práticas da diplomacia brasileira. Emblemático no período foi o conflito de Serra Leoa (1997) em que senhores da guerra lucraram com ajuda humanitária em detrimento da segurança da população local.

\section{As operações de paz}

Contra o modelo monolítico estadunidense, o discurso brasileiro na ONU defende que o intervencionismo pacífico constrói a paz e o engajamento humanitário, contra os senhores da guerra e os etnonacionalistas. Em quadros de escalada e desescalada de conflitos, apontam-se os atuais modelos de solução de controvérsia: peacemaking - quando a violência está instalada e é necessário aplicar solução emergencial; Peacekeeping - para casos em que cessou a violência, ao menos de maneira provisória, e se quer evitar genocídios ou o retorno à violência; e peacebuilding - aplicado em casos de Estados falidos, quando não basta cessar com a violência, mas restaurar a sociedade (GALTUNG, 1969). Além de apoiar tais iniciativas, não sem antes ajustar seu discurso para o fato de que peacemaking e peacekeeping também utilizam a força, o Brasil parece integrar o espectro que vê a violência como o oposto da justiça social. Entende-se que a violência é indireta ou estrutural, ou seja, aquela em que não se identifica $\mathrm{o}$ ator que a gera. É a violência sem a relação sujeito - verbo - objeto, que possa ser descrita como açáo de alguém contra outro alguém; esta sim, violência direta (GALTUNG, 1969, p. 171).

Ilustrativo da necessidade de reforma do Conselho por sua ineficácia em lidar com os conflitos internacionais, o processo de paz de Oslo, em que se buscava apaziguar definitivamente Israel e a Palestina, ruiu em definitivo com uma nova Intifada no ano 2000. No ano seguinte acontecem os ataques ao World Trade Center e ao Pentágono nos EUA e a subsequente 'guerra ao terror' desencadeada por George W. Bush. Em 2003 iniciam-se as ofensivas militares contra o terror, através da Operação Liberdade Iraque. Desde o início da crise dos EUA com o Iraque, o governo FHC, já em vias de encerrar seu segundo mandato, reforçava, por intermédio do ministro Celso Lafer, as orientaçôes fundamentais de sua política externa: democracia, multilateralismo, legitimidade, diálogo e cooperação (SEIXAS CORRÊA, 2007, p. 691). Porém, o apoio à uma ação conjunta concertada entre EUA, Grã-Bretanha e o Conselho de Segurança esbarrou nos incidentes da prisão de $A b u$ Ghraib (2004) e seus desdobramentos negativos. 


\section{A mundialização da política externa brasileira}

Luís Inácio Lula da Silva, por sua vez, deu continuidade à tradição brasileira de seu modo pessoal. Em discurso de abertura da $58^{a}$ Assembleia Geral da ONU, no dia 23 de setembro de 2003, o presidente comentou de forma crítica o mecanismo de veto do Conselho de Segurança, a necessidade de reformar o órgão e de empoderar a Assembleia: "A Assembleia Geral não deve hesitar em assumir suas responsabilidades na administração da paz e segurança internacionais. A ONU já deu mostras de que há alternativas jurídicas e políticas para a paralisia do veto e as ações sem endosso multilateral" (LULA DA SILVA, 2007, p. 701). Na ocasião, Lula homenageou o então recém-falecido chanceler Sérgio Vieira de Mello, morto em missão da ONU em Bagdá, e falou com a autoridade de quem havia mitigado rapidamente as desconfianças quanto ao "comprometimento da nova administração brasileira com a estabilidade macroeconômica" (SEIXAS CORRÊA, 2007, p. 699).

Essa tônica seria incrementada por um discurso cada vez mais voltado contra as desigualdades entre as naçóes. $\mathrm{O}$ Brasil denunciava a situação no Oriente Médio, ressaltando o próprio papel de pacificador no Haiti. Batia-se na tecla da reforma do Conselho, com a premissa de que o fim da violência traria justiça social entre países pobres e ricos. Este foi um período de especial esperança brasileira, pois, embora não houvesse acenos positivos por parte de China e EUA, o então G-4 (Brasil, Índia, Japão e Alemanha) parecia suficiente para forçar a reforma do Conselho de Segurança. Praticou-se entre 2006 e 2010 a 'mundialização' da política externa brasileira (DUARTE VILLA e TRINDADE VIANA, 2010).

O governo Lula deixou de apenas reagir a temas como terrorismo, proposto pelos EUA no pri- meiro mandato, para tornar-se mais assertivo em sua política externa no segundo: além do exemplo das tropas brasileiras no Haiti, há as negociações de paz com as Forças Armadas Revolucionárias Colombianas (FARC). Sustenta-se que o segundo governo Lula propiciou um aumento no escopo da política exterior brasileira, com ênfase a questóes ligadas à energia nuclear no país, na América Latina, e na busca por solução pacífica para as suspeitas de armas de destruição em massa no Iraque (DUARTE VILLA; TRINDADE VIANA, 2010, p. 111).

Também o discurso oficial da presidente Dilma Rousseff, na abertura da 69a Assembleia Geral das Naçôes Unidas, no dia 24 de setembro de 2014, pode ser analisado na tradição de continuidade da política externa brasileira. Ressalte-se a associação do posicionamento brasileiro em relaçáo ao grupo terrorista Estado Islâmico (EI), aos ideais, valores e identidade historicamente construídos pela diplomacia brasileira desde a fundação da Liga das Naçóes (MELLO E SILVA, 1998, p. 148)³. Proferido "um dia depois de os Estados Unidos da América (EUA) terem realizado ataques aéreos contra posições do grupo jihadista Estado Islâmico (EI) na Síria” (DILMA..., 2015), o discurso reforçou a já tradicional posição antibélica brasileira e a crença em mecanismos pacíficos de resolução de controvérsias.

Segundo a presidente, vige na comunidade internacional uma extrema incapacidade em lidar tanto com conflitos históricos quanto em impedir o surgimento de novas crises. Alusivos aos EUA, citaram-se casos como o da Palestina, o massacre de civis na Síria, a desestruturação do Iraque após a morte de Saddam Hussein, o impasse na Líbia e a situação da Ucrânia como provas da incapacidade de uma geração de líderes em resolver velhos pro-

3. Mello e Silva (1998) baseia seus estudos da "dimensão cognitiva da formulaçáo diplomática" em livros como The world in their minds, de Yaakov Vertzberger (1990). Este autor investiga como as visóes de mundo dos policymakers influenciam a formulação de política externa de países que buscam se inserir no topo da ordem diplomática mundial. 
blemas (DILMA..., 2015). Ressaltou-se que o uso da força não atinge as causas profundas dos conflitos, mas os acirra. Além disso, a intervenção militar náo é o caminho para a paz e sim para o aumento no número de vítimas de catástrofes humanitárias. Afirmando que o Brasil está apto a contribuir para um ambiente internacional mais pacífico, em que o ano de 2015 seria o marco desta iniciativa, Dilma Rousseff aproveitou a ocasiáo para mais uma vez pressionar pela reforma do Conselho de Segurança da Organização das Naçóes Unidas (ONU). Note-se, porém, que sob Dilma Rousseff (2011 - 2016) e desde a posse de Michel Temer, em 31 de agosto de 2016, o Brasil não manifestou interesse em integrar o Conselho. O resultado é a suspensão do país dessa instância da ONU até o ano de 2033 (MELLO, 2017).

\section{Conclusão}

Em suma, em momentos históricos distintos, o Brasil defendeu argumentos diplomáticos semelhantes para a sua ascensão ao primeiro time das naçóes concertantes do sistema internacional. São estes momentos o imediato pós-Primeira Guerra Mundial, com a criação da Liga das Naçôes; a criação da ONU sobre as cinzas da Liga ainda durante a Segunda Guerra; a virada de uma estrutura multipolar para a bipolaridade da Guerra Fria e a contemporaneidade, em que se recupera a crença em arranjos multilaterais e em instituiçóes que reflitam a nova ordem mundial. É nestes momentos que se expressam concepçóes nacionais das noçóes de papel, status e pertencimento do Brasil ao sistema internacional (VERTZBERGER, 1990). Projeta-se no ambiente externo, por meio do discurso de eficiência, a imagem idealizada da identidade nacional em termos de "atributos culturais, econômicos, demográficos, geográficos e político-econômicos" (MELLO E SILVA, 1998, 148).
Há uma grande preocupação com a segurança em tempos de paz (KOLODZIEJ, 2005), mas percebe-se que o Brasil compreende as limitações dos mecanismos pacíficos de solução de controvérsias (MIAL et al. , 2005). Porém, mesmo reconhecendo as limitaçôes das operaçóes, o Brasil entende estes movimentos como em busca de justiça social em oposição à violência direta ou indireta que se desenvolve no sistema. Em contrapartida, verifica-se uma má percepção do país ao comunicar sua política externa frente à diferentes situaçóes históricas. Há, por assim dizer, "discrepância entre o mundo real (objetivo) e sua representação mental (subjetiva)" (LITTLE e SMITH, 1988; MELLO E SILVA, 1998, p. 143). Ou seja: o Brasil vem projetando no sistema uma imagem idealizada de seu papel, algumas vezes acertadamente; outras, em discordância com a realidade de suas capacidades material e de articulação política. A atual suspensão do país do Conselho de Segurança da ONU por um período mínimo de 22 anos é um dos exemplos do encolhimento diplomático do país ao longo de sua história.

\section{Referências}

AMORIM, Celso. XLIX Sessão Ordinária da Assembleia Geral da ONU. In: Luiz Felipe de Seixas Corrêa (org.) O Brasil nas Naçóes Unidas: 1946 - 2006. Brasília: Fundação Alexandre de Gusmão. 2007. P. 581 - 589

CERVO, Amado Luiz; BUENO, Clodoaldo. História da política exterior do Brasil. - 2. ed. - Brasília. Editora Universidade de Brasília, 2002.

CERVO, Amado Luiz. Eixos conceituais da política exterior do Brasil. Revista Brasileira de Política Internacional, 41. No spe. Brasília, 1998. Disponível em: <http://www.scielo.br/scielo.php?script=sci_arttext\&pid=S003473291998000300005>. Acesso em: 21 mar. 2014.

DILMA condena uso generalizado da força na ONU. Carta Capital. 24 set. 2014. Disponível em: <http://www.cartacapital.com.br/internacional/dilma-condena-uso-generalizado-da-forca-na-onu-1522.html>. Acesso em: 01 maio 2015.

DUARTE VILLA, Rafael Antônio; TRINDADE VIANA, Manuela. Security Issues during Lula's Admnistration: from the 
reactive to the assertive approach. In: Revista Brasileira de Política Internacional. No 53 (special edition): 91 - 114. 2010.

GALTUNG, Johan. Violence, Peace and Peace Research. Journal of Peace Research, V. 6, No 3 (1969), P. 167 - 191.

GARROT, Emmanuel et al. Un regard sur l'historiographie de la politique extérieure brésilenne aux Xxe siècle. In: Dennis Rolland (coord.). Le Brésil e Le Monde. Pour une histoire des relations internationales de puissances émergentes.Paris: L'Harmattan, 1998.

KOLODZIEJ, Edward A. Security and International Relations. New York: Cambridge University Press. 2005. 349 p.

LAMPREIA, Felipe. L Sessão Ordinária da Assembleia Geral da ONU. In: Luiz Felipe de Seixas Corrêa (org.) O Brasil nas Naçóes Unidas: 1946 - 2006. Brasília: Fundação Alexandre de Gusmão. 2007. P. 595 - 605.

LITTLE, Richard e SMITH, Steve (ed.). Belief Systems and International Relations. Oxford/New York: Basil Blackwell, 1988.

LULA DA SILVA, Luís Inácio. LVIII Sessão Ordinária da Assembleia Geral da ONU. In: Luiz Felipe de Seixas Corrêa (org.) O Brasil nas Naçóes Unidas: 1946 - 2006. Brasília: Fundação Alexandre de Gusmão. 2007. 768 p.

MELLO, Patrícia Campos. Brasil ficará de fora do Conselho de Segurança da ONU ao menos até 2033. Folha de Sáo Paulo. 17 mar. 2017.disponível em: < http://www1.folha.uol.com. $\mathrm{br} / \mathrm{mundo} / 2017 / 03 / 1867280$-brasil-ficara-de-fora-do-conselho-de-seguranca-da-onu-ao-menos-ate-2033.shtml>. Acesso em: 22 mar. 2017.

MELLO E SILVA, Alexandra. Ideias e Política Externa: a atuaçáo do Brasil na Liga das Naçóes e na ONU. Rio de Janeiro: Revista Brasileira de Política Externa Internacional. 41 (2): pp. 139 - 158, 1998.

MIALL, Hugh; RAMSBOTHAM, Oliver; WOODHOUSE, Tom. Contemporary Conflict Resolution: the prevention, management and transformation of deadly conflicts. UK: Polity Ed. Cambridge. 2005. Caps. 1 e 2.

SARNEY, José. XL Sessão Ordinária da Assembleia Geral da ONU. In: Luiz Felipe de Seixas Corrêa (org.) O Brasil nas Naçóes Unidas: 1946 - 2006. Brasília: Fundação Alexandre de Gusmão. 2007. P. 445 - 459.

SEIXAS CORREAA, Luiz Felipe de. In: Luiz Felipe de Seixas Corrêa (org.). O Brasil nas Naçóes Unidas: 1946 - 2006. Brasília: Fundação Alexandre de Gusmão. 2007. 768p.c

VERTZBERGER, Yaacov. The World in their Minds: Information Processing, Cognition and Perception in Foreign Policy Decision Making. Stanford: Stanford University Press, 1990. 